"نشريه علوم زراعى ايران"

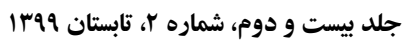

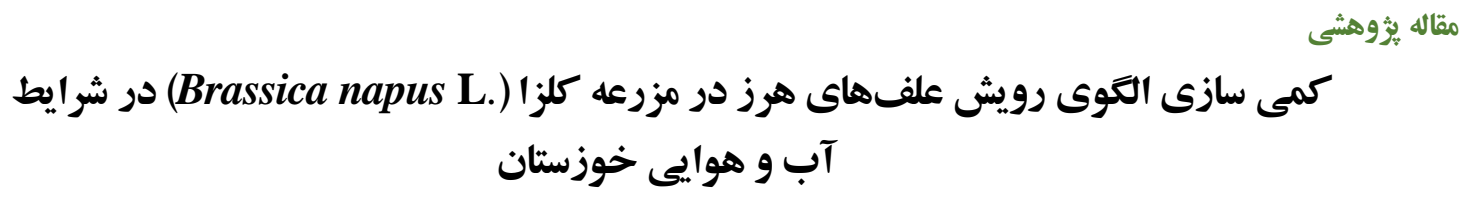

Quantifying field weeds emergence pattern in rapeseed (Brassica napus L.) under weather conditions of Khuzestan, Iran

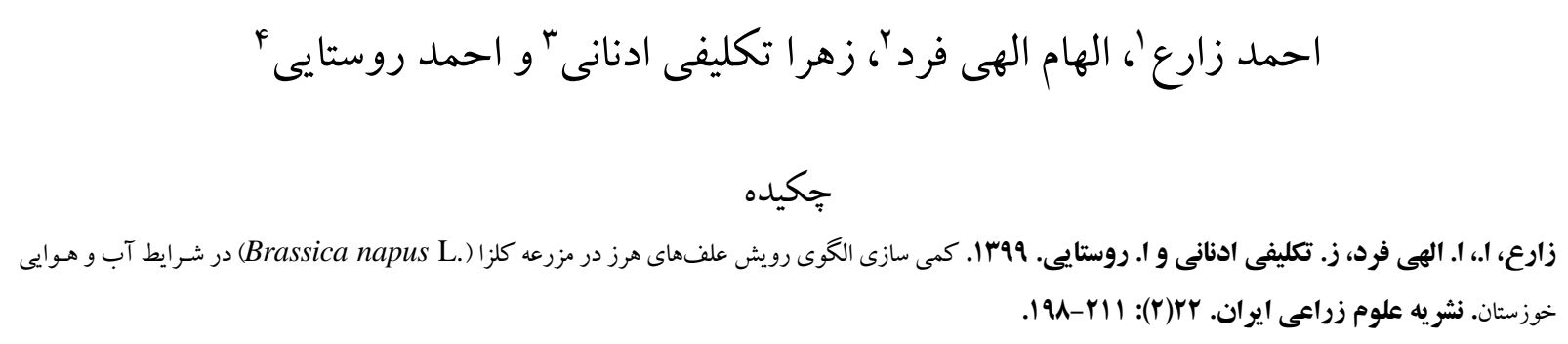

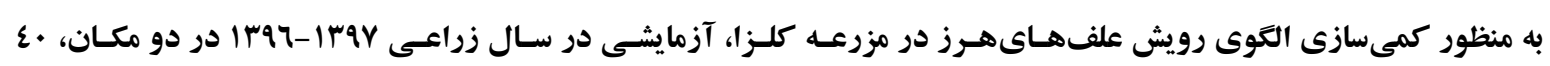

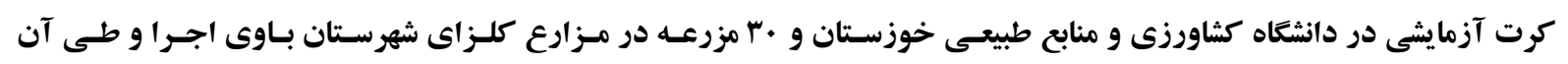

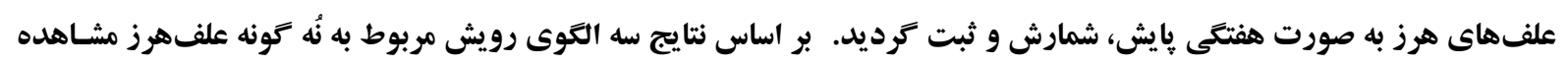

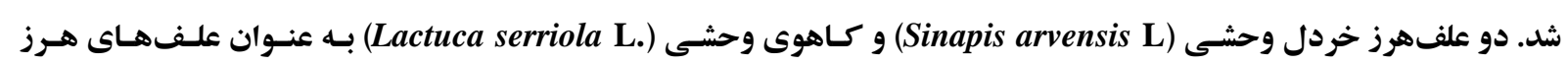

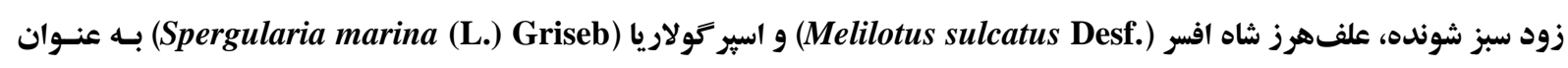

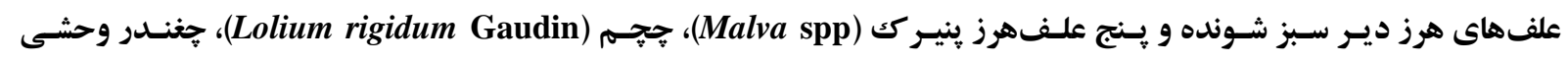
(Beta vulgaris subsp. maritima (L.) Arcangeli) (Chenopodium murale L.)

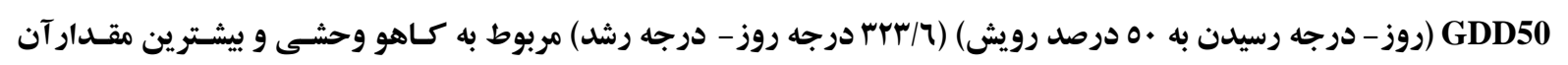

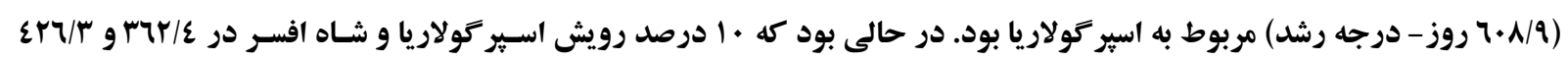

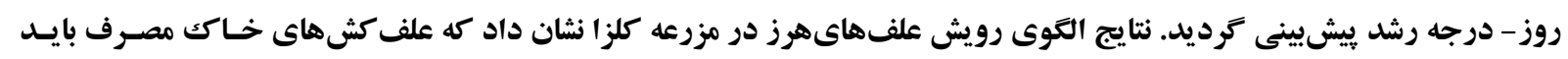

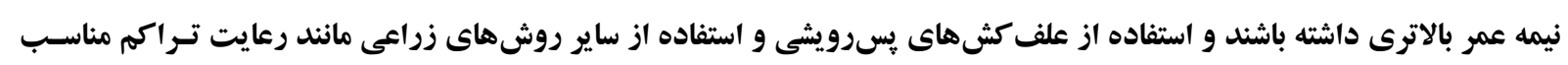

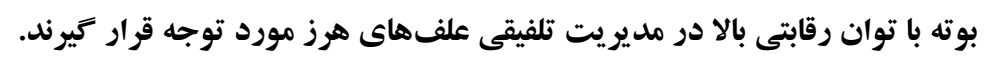

وازههاى كليدى: روز - درجه رشد، علفهاى هرز دير سبز شونده، علفهاى هـرز زود سـبز شـونده، كلـزا و مـديريت تلفيقى

علفهاى هرز.

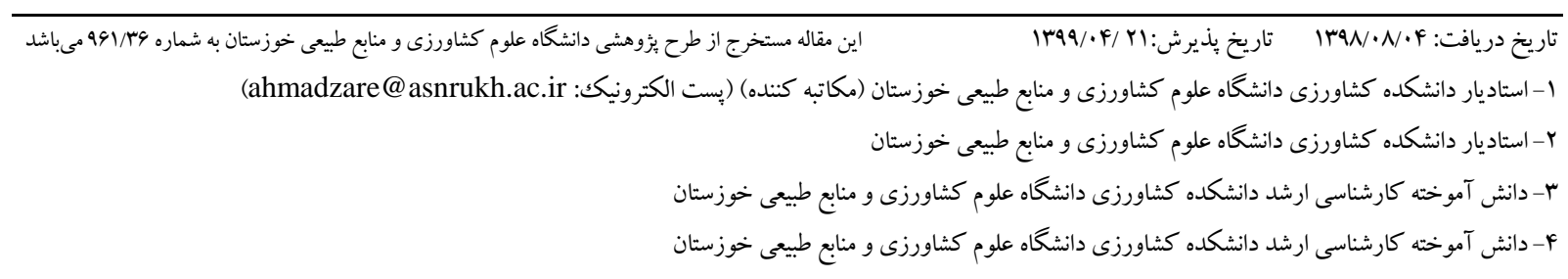


كندم سبز شدند (Scursoni et al., 1999). نتايج آزمايش

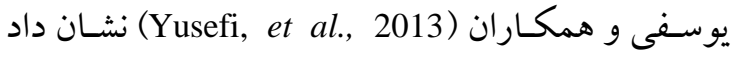

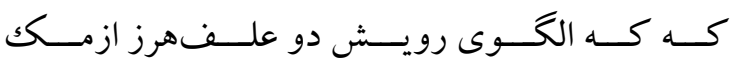
(Descurainia sophia) و خاكشيس دو (Cardaria draba)

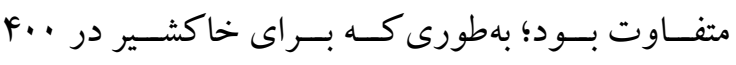

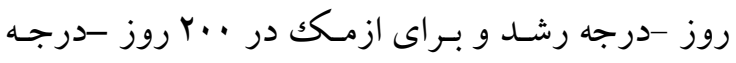
رشد كليه بذرهاى موجـود درخـاكك سـبز شـدند. نتـايج

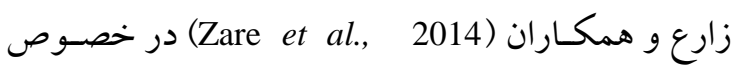

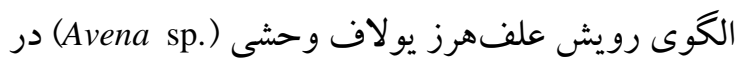

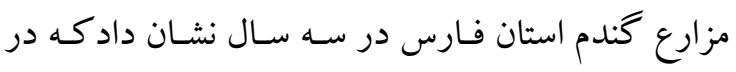

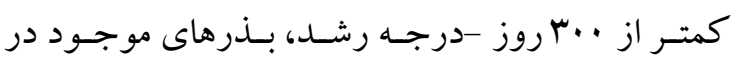

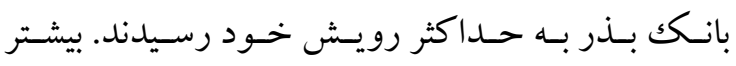

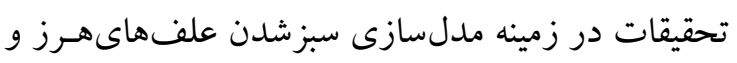

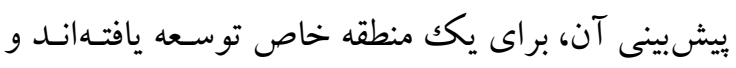

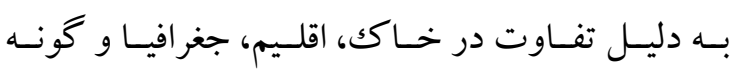
علف هرز ممكـن اسـت بـراى همـه منـاطق قابـل تعمـيم

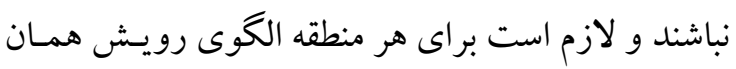
منطقه مورد ارزيابى قرار گيرد (Myers et al., 2004). با توجه به نياز كشـور بـه محصسول كلـزا بـه منظور

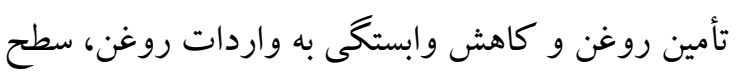

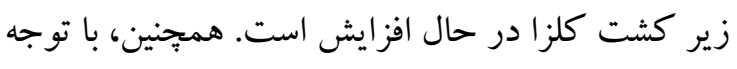

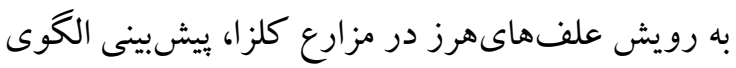

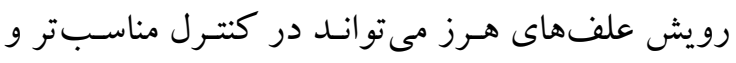

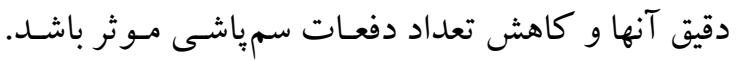

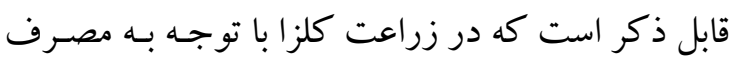

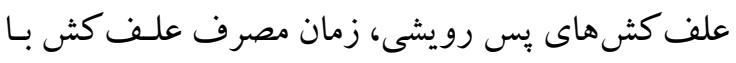

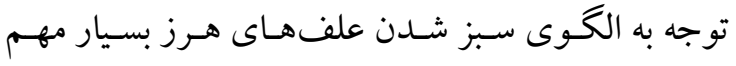

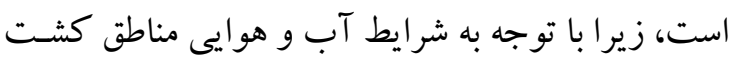

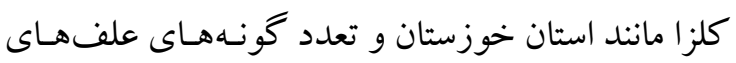
هرز، احتمال فرار از علف كث توسط برخى گونهها بعد

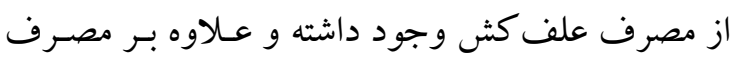

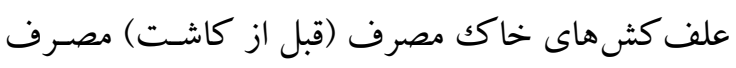
علف كشهاى بِ بسرويشى براى كونههاى كه بعـداً سـبز

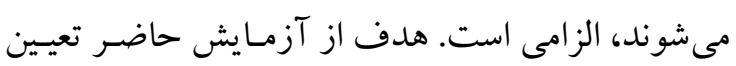

\section{مقدمه}

بيشبينسى زمـان رويسش علفهـاى هـرز در مزرعــه

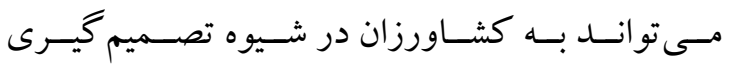

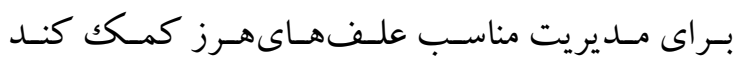

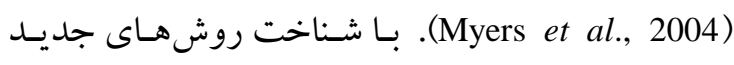

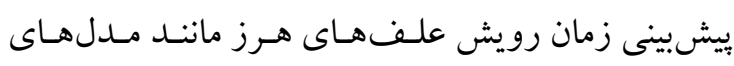

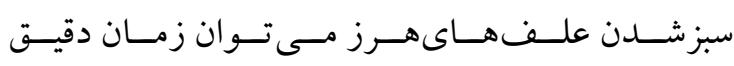

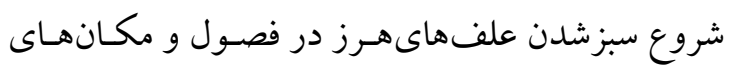

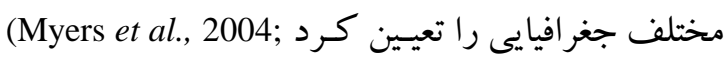
.Cardina et al., 2011) اولين مدلهاى مكانيستيك سبز شدن علف مهاى هرز

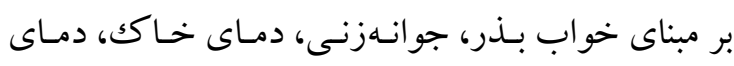

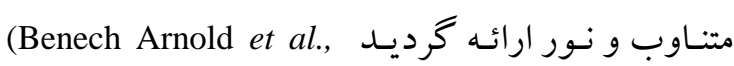
1990; Forcella, 2000) هستند كه براى بيشبينى سبز شدن علفهاىهـرز مـورد

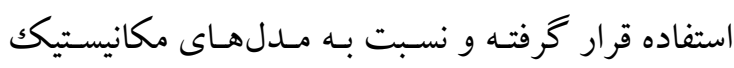

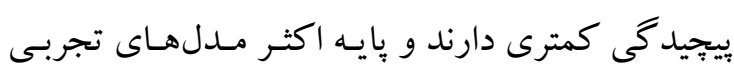
بر آورد زمان مطلوب مىباشـيند (Forcella et al., 2000).

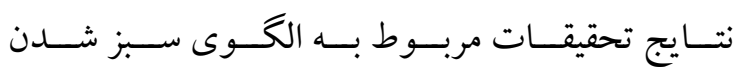
علف هاىهرز تاجخـروس (Amaranthus rudis Sauer)،

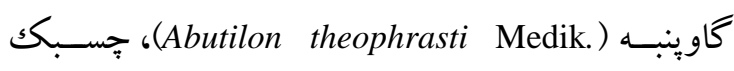

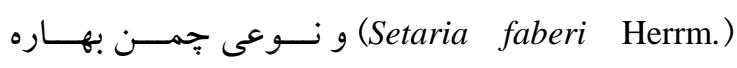
طسى سـه سـال (Eriochloa villosa (Thunb.) Kunth) آزمايش نشان داد كه مراحل سبزشـدن در هـر سـه سـال

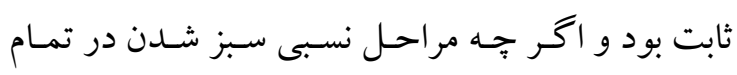

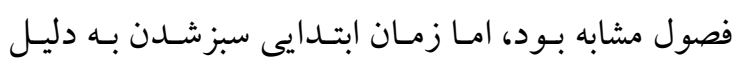

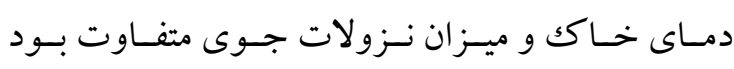

.(Hartzler et al., 1999)

بنـا بـه گــزارش فرانكـهـ (Franke et al., 2007).

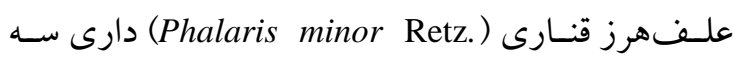
زمان سبز شدن بود و اولين زمان سبز شدن آن در مزرعه

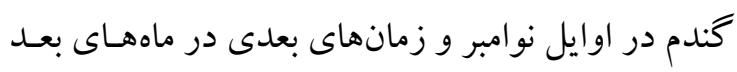

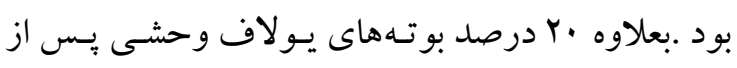

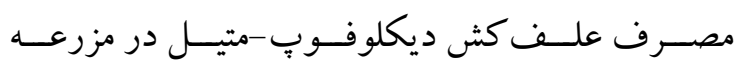




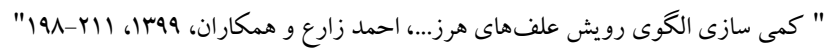

مترمربع شمارش و يادداشتبردارى شـد. تـاريخ كشـت

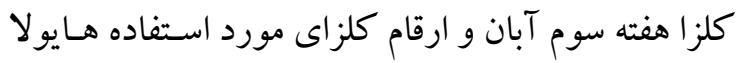

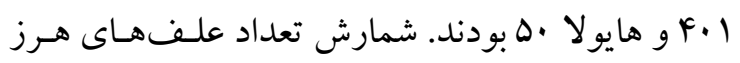

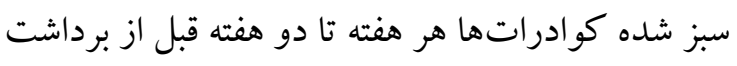

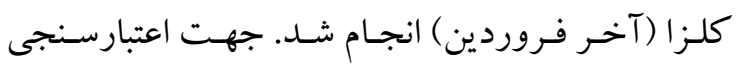

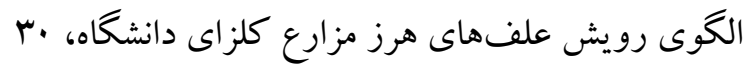

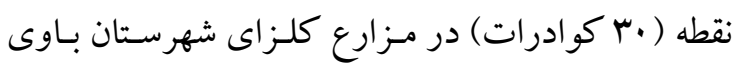

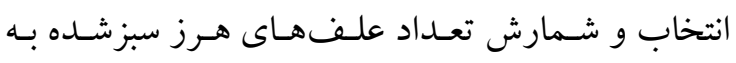

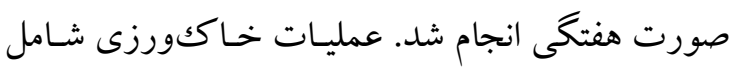

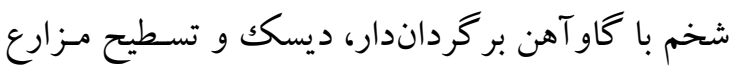

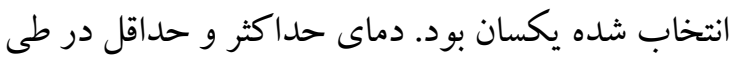
فصل رشد در جدول انشان داده شده است.
الكوى رويش علف هاىهرز در مزرعه كلـزا در شـرايط آب و هوايى شهرستان باوى استان خوزستان بوده.

\section{مواد و روشها}

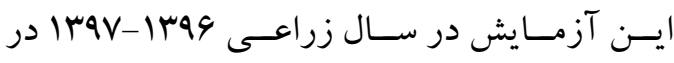

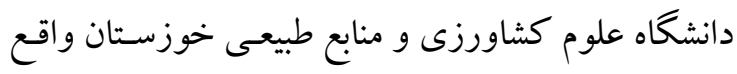

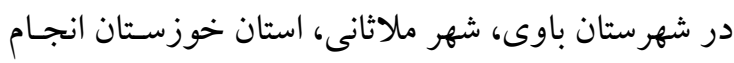

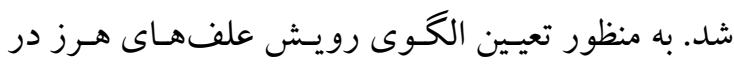

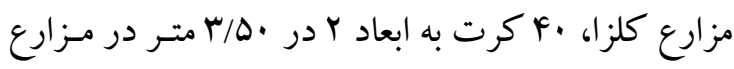

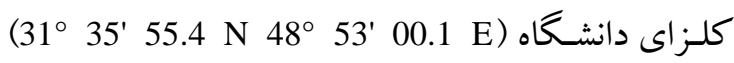
انتخاب شده و رويش گونههاى علف هاى هرز (تعداد و

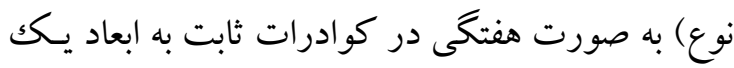

\section{جدول ا - ميانگين دماى حداكثر و حداقل در طول دوره رويش كلزا}

Table1. Mean of maximum and minimum temperature during growing period of rapeseed

دماى حداكثر : Max.

\begin{tabular}{|c|c|c|}
\hline & Min. temperature $\left({ }^{\circ} \mathrm{C}\right)$ & Max. temperature $\left({ }^{\circ} \mathrm{C}\right)$ \\
\hline Oct. مهر & 17.7 & 35.6 \\
\hline Nov. Tبان & 14.7 & 31.8 \\
\hline Dec. آذذر & 6.7 & 21.0 \\
\hline Jan. Ja Jan & 7.5 & 20.2 \\
\hline Feb. بهمن & 5.6 & 19.5 \\
\hline Mar. اسفند & 10.1 & 25.4 \\
\hline
\end{tabular}

\section{روز-درجه رشد و b: شيب خط در نقطه c هستند.}

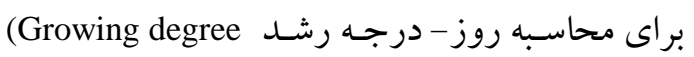
days)

$\mathrm{GDD}=\Sigma\left(\frac{\mathrm{T}_{\max }+\mathrm{T}_{\min }}{2}\right)-\mathrm{T}_{\text {base }}$

(رابطه

Tماى حداكثر در عمق بنج سانتىمترى خـاكك،

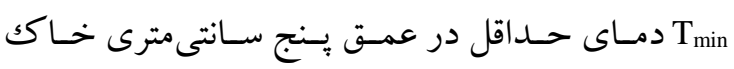
و Tماى بايه (صفر گياهى) هستند.

\section{نتايج و بحث}

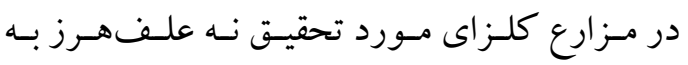

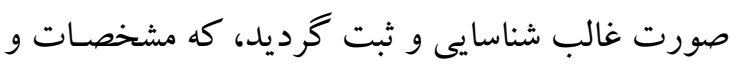

دماى بايه براى جوانهزنى در جدول ذيل بيان شده است

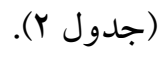

رويش علفهاى هرز سبز شده داخل هر كوادرات

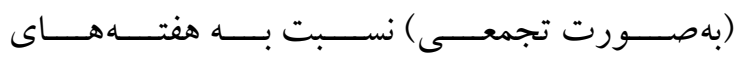

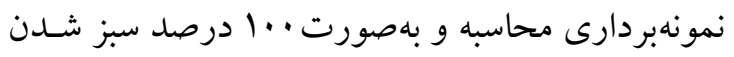

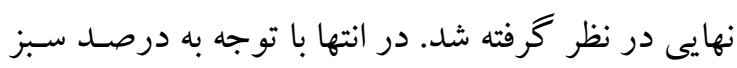
شدن علف هاى هرز، رويش تجمعى هر گونه با استفاده

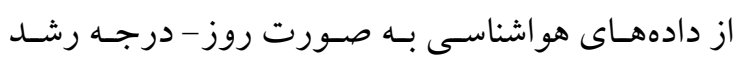
محاسبه شد.

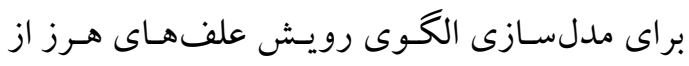

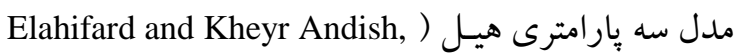

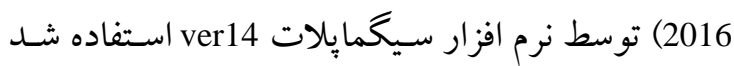

$\mathrm{E}=\frac{100 * \mathrm{GDD}^{\mathrm{b}}}{\left(\mathrm{c}^{\mathrm{b}}+\mathrm{GDD}^{\mathrm{b}}\right)}$

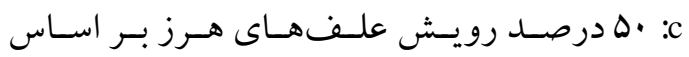


جدول r- علف هاى هرز شناسايى شده در مزارع كلزا و دماى بايه جوانهزنى آنها

Table 2. Identified weeds in rapeseed fields and their germination base temperature

\begin{tabular}{|c|c|c|c|}
\hline $\begin{array}{c}\text { نام عمومى } \\
\text { Common name }\end{array}$ & $\begin{array}{c}\text { نام علمى } \\
\text { Scientific name }\end{array}$ & $\begin{array}{c}\text { دماى بِايه } \\
\text { Base temperature }\end{array}$ & $\begin{array}{c}\text { منابع } \\
\text { References } \\
\end{array}$ \\
\hline $\begin{array}{c}\text { خردل وحشى } \\
\text { Wild mustard }\end{array}$ & Sinapis arvensis $\mathrm{L}$. & $2^{\circ} \mathrm{C}$ & Khalaj et al., 2012 \\
\hline كاهوى وحشى & Lactuca serriola $\mathrm{L}$. & $5^{\circ} \mathrm{C}$ & Kazerooni Monfared et al., 2012 \\
\hline $\begin{array}{c}\text { حَنير كك } \\
\text { Mallow }\end{array}$ & Malva spp. & $1^{\circ} \mathrm{C}$ & Ansari et al., 2016 \\
\hline Milk thistle & Silybum marianum (L.) Gaertn. & $1.35^{\circ} \mathrm{C}$ & Pourreza and Bahrani, 2012 \\
\hline $\begin{array}{c}\text { سلمك برك كزنهاى } \\
\text { Nettle-leaved goosefoot }\end{array}$ & Chenopodium murale $\mathrm{L}$. & $4^{\circ} \mathrm{C}$ & Elkarmi et al., 2009 \\
\hline Sea beet & Beta vulgaris subsp. maritima (L.) Arcangeli & $3^{\circ} \mathrm{C}$ & Biancardi et al., 2012 \\
\hline Rigid ryegrass & Lolium rigidum Gaudin & $5^{\circ} \mathrm{C}$ & Goggin et al., 2012; Steadman et.al., 2003; Owen et al., 2011 \\
\hline $\begin{array}{l}\text { زمين گستر شورروى } \\
\text { Salt sandspurry }\end{array}$ & Spergularia marina (L.) Griseb. & $4^{\circ} \mathrm{C}$ & Carter and Ungar, 2004 \\
\hline $\begin{array}{c}\text { شاه افسر } \\
\text { Furrowed melilot }\end{array}$ & Melilotus sulcatus Desf. & $0^{\circ} \mathrm{C}$ & Ghaderi-far et al., 2010 \\
\hline
\end{tabular}




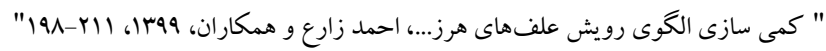

به علف هاىهرز سبز شـده وايسـين يـا ديـر سـبز شـونده نـام كـذارى شـدند، دو كونسه (Last-Emerging Weeds) شاهافسر و اسـير گولاريا (زمسين گسـتر شـور روى) قـرار كر فتند. معادله سـه بـار امترى هيـل، رويسش تجمعسى بـر

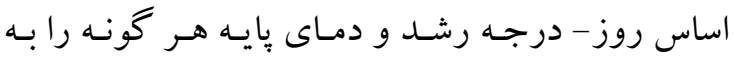
خوبى توصيف كرد (جدول و شكل (). ضريب تبيسين اصلاح شده (R (R ) نتايج نشـان داد كـه ايـن معادله در ييشبينى رويش علفهاىهرز مورد مطالعه مناسب بوده

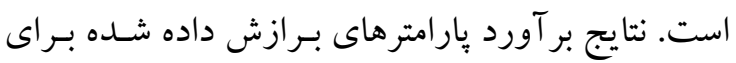
•ه درصد سبزشدن نشان داد كـه بيشـترين روز - درجـه رشـد بـر آورد شـده مربـوط بـه اسـير كولاريا و كمتـرين روز - درجه رشد بر آورد شده مربوط بـه كـاهو وحشى نـى

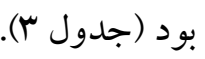

ييشبينى الكوى رويش علفهاىهرز كلز ا نشان داد كه زمان سبز شدن در بين علفهاىهرز در مزارع كلـزا

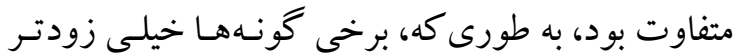

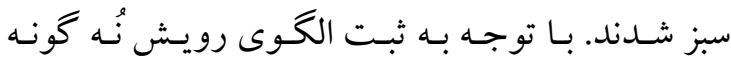
علف هرز (جدول Y)، سه نوع سبز شـدن مشـاهده شـد و كونهها بر اين اساس به سه كروه تقسـيمبندى شـدند. در كروه اول كه با عنوان علـف هــاىهـرز زود سـبز شـونده

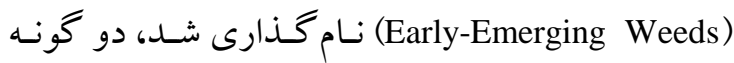
خردل وحشى و كاهوى وحشى قرار گرفتند. در گروه دوم كه به عنوان علف هاى هرز سبز شونده حدواسط يـا

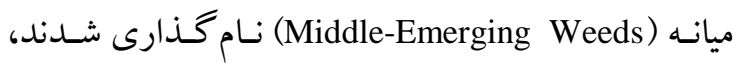

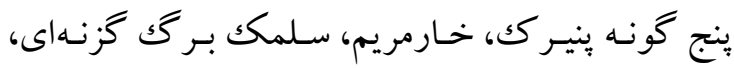

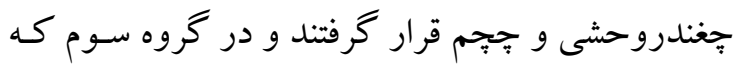

جدول ب- يارامترهاى بيشبينى شده رويش تجمعى علف هاى هرز كلزابر اساس معادله هيل

Fig. 3. Estimated parameters of cumulative emergence of rapeseed weed species based on Hill equation

\begin{tabular}{|c|c|c|c|}
\hline $\begin{array}{c}\text { گرووه } \\
\text { Category }\end{array}$ & $\begin{array}{c}\text { نام علمى } \\
\text { Scientific name }\end{array}$ & $\begin{array}{c}\text { Jeم } \\
\text { Hill equation }\end{array}$ & $\begin{array}{c}\text { ضريب تبيين اصلاح شده } \\
\mathrm{R}^{2 \text { adj }}\end{array}$ \\
\hline \multirow{2}{*}{ علفهاىهرز زود سبزشونده } & Sinapis arvensis $\mathrm{L}$. & $\mathrm{E}=\left(100 * \mathrm{GDD}^{2.43}\right) /\left(383.09^{2.43}+\mathrm{GDD}^{2.43}\right)$ & 0.96 \\
\hline & Lactuca serriola $\mathrm{L}$. & $\mathrm{E}=\left(100 * \mathrm{GDD}^{2.82}\right) /\left(323.62^{2.82}+\mathrm{GDD}^{2.82}\right)$ & 0.85 \\
\hline \multirow{5}{*}{ علف هاى هرز سبز شونده حدواسط } & Malva spp. & $\mathrm{E}=\left(100 * \mathrm{GDD}^{2.69}\right) /\left(458.07^{2.69}+\mathrm{GDD}^{2.69}\right)$ & 0.86 \\
\hline & Silybum marianum (L.) Gaertn. & $\mathrm{E}=\left(100 * \mathrm{GDD}^{2.59}\right) /\left(483.99^{2.59}+\mathrm{GDD}^{2.59}\right)$ & 0.95 \\
\hline & Chenopodium murale $\mathrm{L}$. & $\mathrm{E}=\left(100 * \mathrm{GDD}^{3.31}\right) /\left(386.01^{3.31}+\mathrm{GDD}^{3.31}\right)$ & 0.94 \\
\hline & Beta vulgaris subsp. maritima (L.) Arcangeli & $\mathrm{E}=\left(100 * \mathrm{GDD}^{3.71}\right) /\left(388.32^{3.21}+\mathrm{GDD}^{3.71}\right)$ & 0.96 \\
\hline & Lolium rigidum Gaudin & $\mathrm{E}=\left(100 * \mathrm{GDD}^{4.04}\right) /\left(357.22^{4.04}+\mathrm{GDD}^{4.04}\right)$ & 0.98 \\
\hline \multirow{3}{*}{ علفهاىهرز دير سبز شونده } & Spergularia marina (L.) Griseb. & $\mathrm{E}=\left(100 * \mathrm{GDD}^{4.22}\right) /\left(608.93^{4.22}+\mathrm{GDD}^{4.22}\right)$ & 0.85 \\
\hline & Melilotus sulcatus Desf. & $\mathrm{E}=\left(100 * \mathrm{GDD}^{6.10}\right) /\left(606.50^{6.10}+\mathrm{GDD}^{6.10}\right)$ & 0.96 \\
\hline & Total weeds & $\mathrm{E}=\left(100 * \mathrm{GDD}^{3.13}\right) /\left(435.05^{3.13}+\mathrm{GDD}^{3.13}\right)$ & 0.85 \\
\hline
\end{tabular}

روز - درجه رشد بود (شكل ا و جدول r). دوره كامـل سبز شدن كاهوى وحشى نسبت به خردل وحشى تقريبـاً

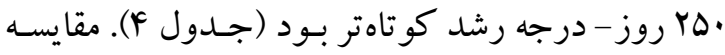
•ه درصـد ســز شــدن در بـين دو كونـه نشـان داد كـهـ كـاهوى وحشـى نيـاز بـهـ روز - درجسه رشـد كمتـرى

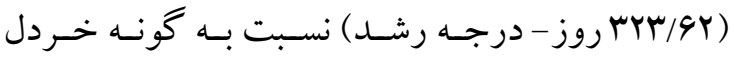

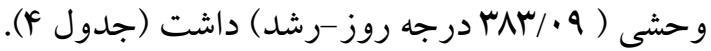
نتايج يكك تحقيقات نشـان داد كـه حـداكثر رويسش علــف-هــرز خــردل در ســه مككـان از •ها تــا ...ه روز - درجه متفاوت بود (Dorsainvil et al., 2005). اين
بيشبينى الكوى سبز شدن در بين دو گونه زود سـبز شونده نشـان داد كـه كـاهوىوحشـى نسـبت بـه خـردل وحشى داراى سبزشدن سريعترى بـود، زيـرا · ل درصــ سبز شدن در IFN/V روز - درجه رشد حسادث كرديـد و در خردل وحشى ·ا درصد سـبز شـدن در DF/A روزدرجه رشد ثبـت كرديـا (شـكل ا و جـدول \&). مقـدار روز درجه رشد مورد نياز براى هو درصد سبز شـدن در بين كونههاى علف هاى هرز متفاوت بـود، بـه طورى كـه ه9 درصد سبز شدن خردل وحشى و كاهوى وحشى بـه

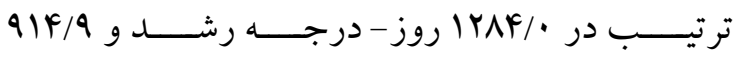




\section{"نشريه علوم زراعى ايران"، جلد بيست و دوم، شماره r، تابستان 99ب1}

خاككورزى با ديسك نسـبت بـه گَاو آهن بر گـر داندار

بيشـتر بـود. آنهـا كَز ارش كردنـد كـه عمـق كاشـت و و قرار گيرى بذر، دماى خـاكك و محتـوى آب خـاكك، در مقايسه با ساختار بستر خـاكك، تـأثير بيشـترى بـر رويسش

علف هرز خردل وحشى دارد.
محققان بيان كردند كه رويش علفهرز خـردل وحشى مى تواند تحت تاثير دمـاى خـاكك، سيسـتم خـاككورزى

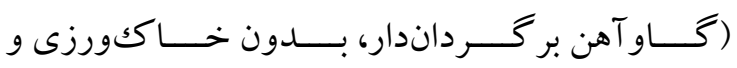
خاككورزى حفاظتى) و عمت قرار گيـرى بـــر درخـاكى قرار گيـــد، بـهورى كـه درصـد رويسش علـفهـرز در

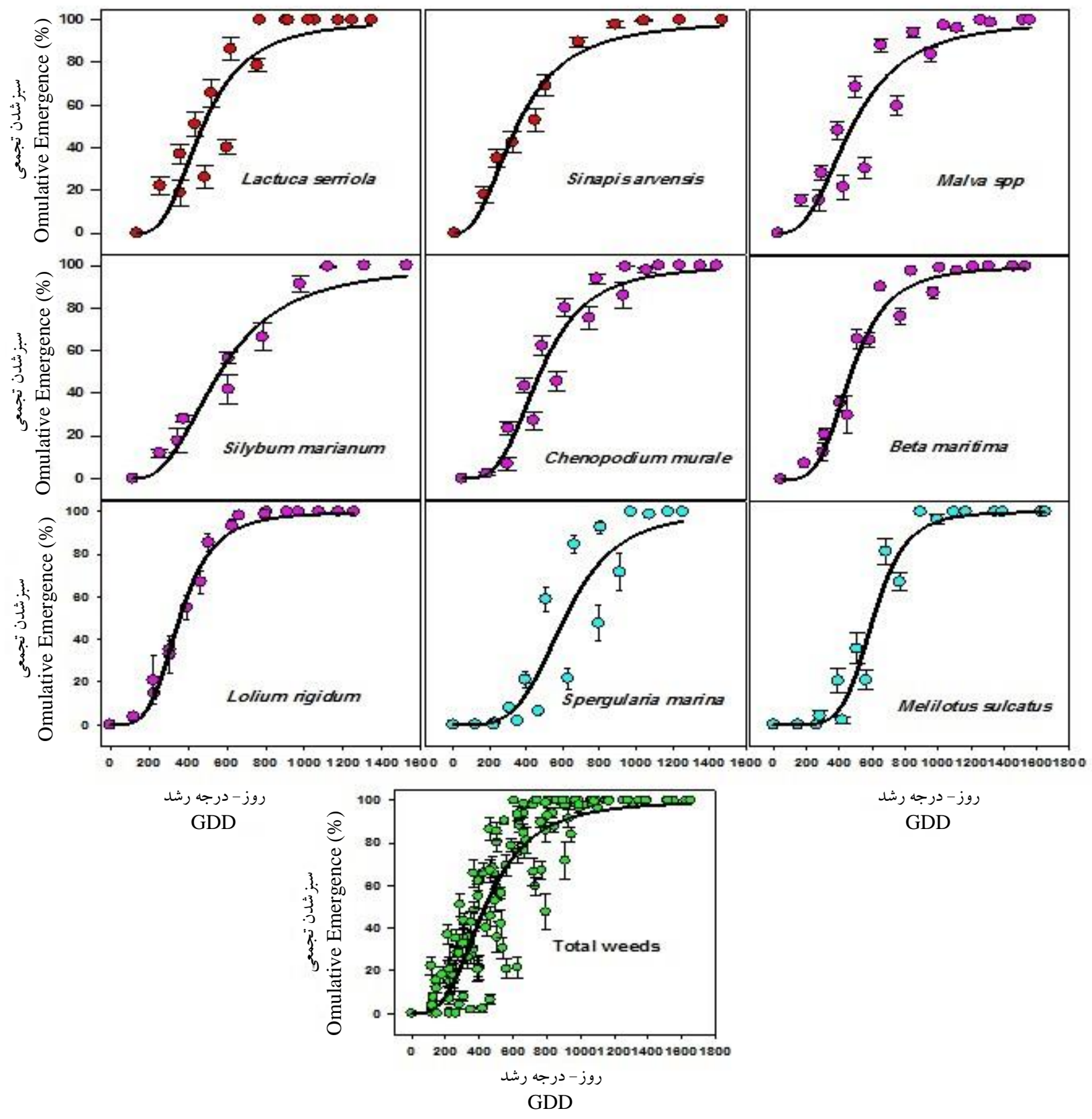

شكل ا- مقادير مشاهده شده (علامت ها) و بيش بينى شده (خطوط ) رويش تجمعى علف هاى هرز در مزرعه كلز ابا استفاده از معادله هيل

Fig. 1. Observed (symbols) and predicted (lines) cumulative emergence of weed species in rapeseed field using Hill equation 


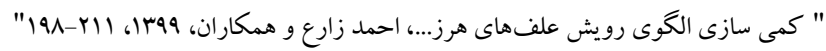

جدول F- روز-درجه رشد مورد نياز براى ·(ه، ·r، ·ه، ·Vو هو درصد رويش علفهاى هرز در مزرعه كلزا

Table 4. Required growing degree day for 10, 30, 50, 70 and 95\% cumulative emergence of weed

species in rapeseed field

\begin{tabular}{|c|c|c|c|c|c|c|}
\hline \multirow{2}{*}{$\begin{array}{c}\text { گروه } \\
\text { Category }\end{array}$} & \multirow{2}{*}{$\begin{array}{c}\text { نام علمى } \\
\text { Scientific name }\end{array}$} & \multicolumn{5}{|c|}{$\begin{array}{c}\text { سبز شدن تجمعى Cumulative emergence } \\
\text { (\%) (2ute }\end{array}$} \\
\hline & & $10 \%$ & $30 \%$ & $\% 50$ & $70 \%$ & $\% 95$ \\
\hline \multirow{3}{*}{ Early-emerging species } & Sinapis arvensis $\mathrm{L}$. & 154.85 & 270.67 & 383.09 & 541.99 & 1284.01 \\
\hline & Lactuca serriola $\mathrm{L}$. & 148.73 & 239.87 & 323.62 & 437.18 & 914.92 \\
\hline & Malva spp. & 200.95 & 333.82 & 458.07 & 625.11 & 1359.57 \\
\hline \multirow{4}{*}{ Middle-emerging species } & Silybum marianum (L.) Gaertn. & 207.64 & 350.03 & 483.99 & 670.40 & 1501.09 \\
\hline & Chenopodium murale $\mathrm{L}$. & 195.90 & 298.75 & 386.01 & 499.56 & 940.35 \\
\hline & Beta vulgaris subsp. maritima (L.) Arcangeli & 216.81 & 312.03 & 388.22 & 486.52 & 856.70 \\
\hline & Lolium rigidum Gaudin & 210.59 & 288.96 & 357.22 & 440.78 & 739.54 \\
\hline \multirow{3}{*}{ Late-emerging species } & Spergularia marina (L.) Griseb. & 362.42 & 499.78 & 608.93 & 744.44 & 1219.51 \\
\hline & Melilotus sulcatus Desf. & 426.37 & 529.73 & 606.50 & 697.69 & 981.94 \\
\hline & Total weeds & 219.64 & 330.56 & 435.05 & 570.45 & 1111.14 \\
\hline
\end{tabular}

درصد بذرهاى آنها در بانـك بـذر، نسـبت بـه دو گونـه

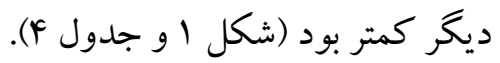

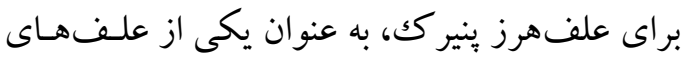

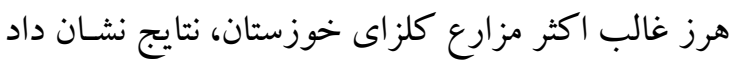

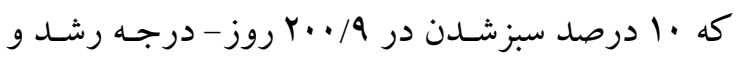
هو درصسد سـبز شــن در اتفاق افتاد، بنابر اين مى توان انتظار داشت كـه بنيـرك بـ بـا توجه به دارا بودن ميوه شيزو كاربٍ و بوشش بذر، بـراى جذب آب توسط بذر و شروع مراحل جوانهزنى، نياز به زمان بيشترى داشته باشد. بعلاوه دورههاى طـولانى سـبز شدن در اين علفهرز مى تواند به يوشش بـذر و خـواب بــاب بذر آن مربوط باشد.

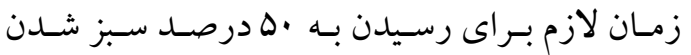
در گروه علفهاى هرز سبزشونده حد واسط نشـان داد

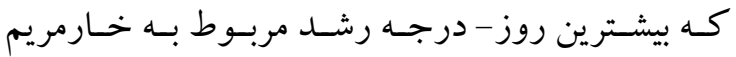

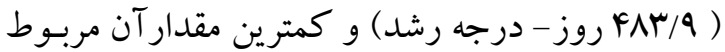

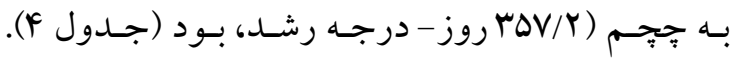

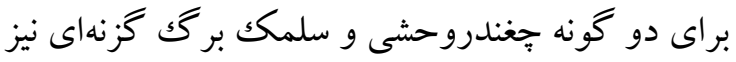

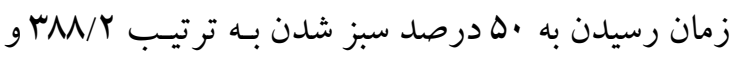

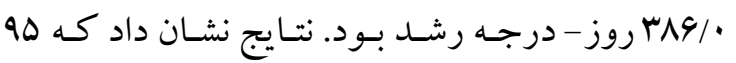

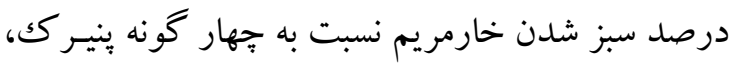

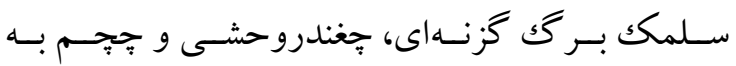

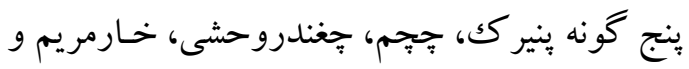

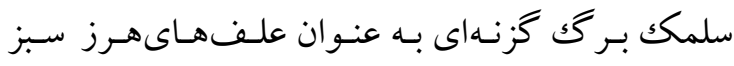

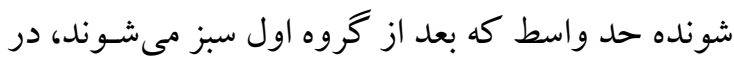

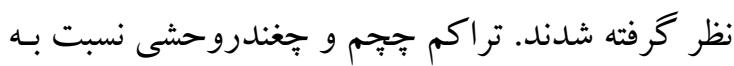

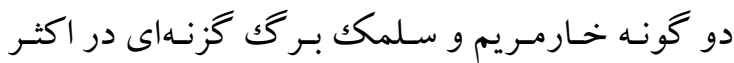
مزارع بيشتر بود (دادهها ارائه نشده است). روند تغييرات

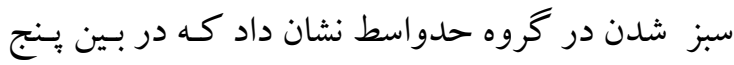

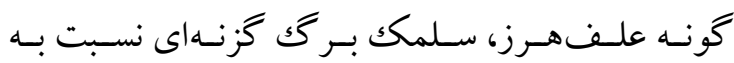
سايرعلف هاى هـرز سـرعت سبزشــن بيشـترى داشـت،

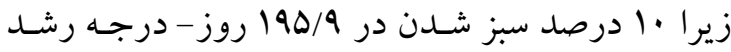

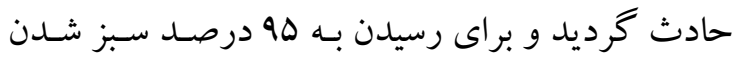

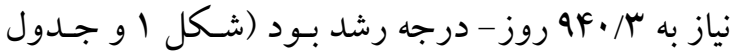

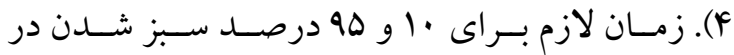

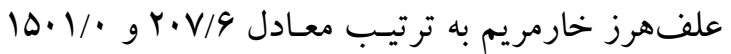

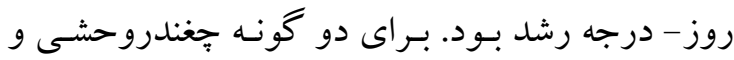

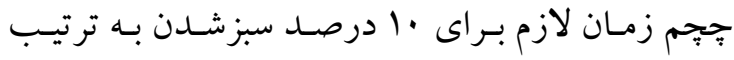

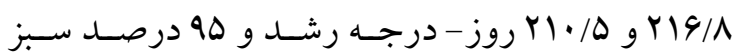

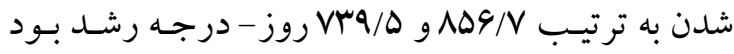

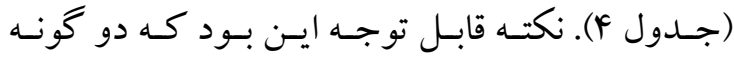

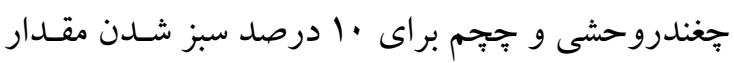

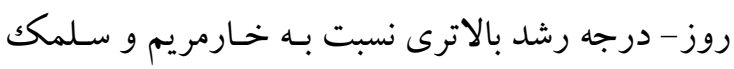

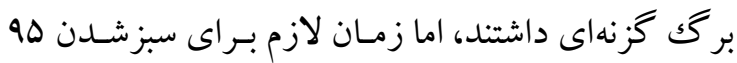




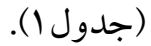

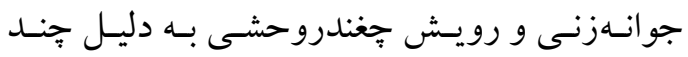

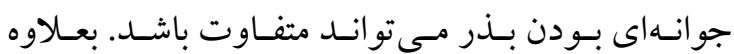

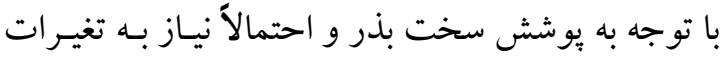

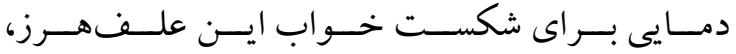
تغييـرات رفتـار جوانسهزنسى و رويسش ممكـن اسـت در در

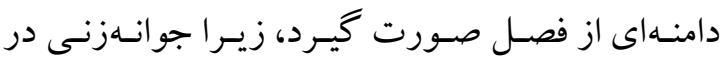

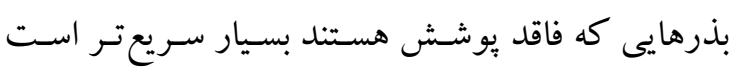

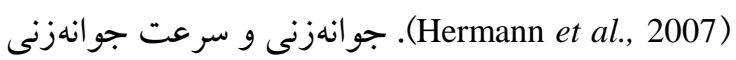

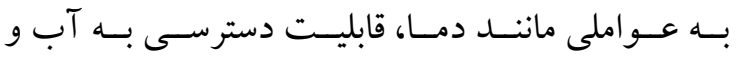

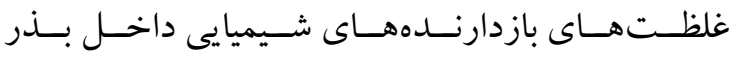

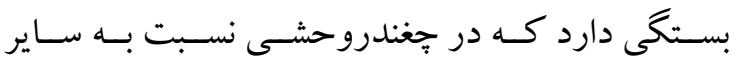

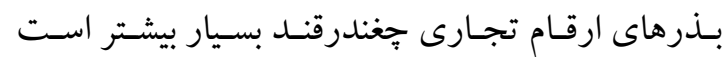
(Morris et al., 1984)

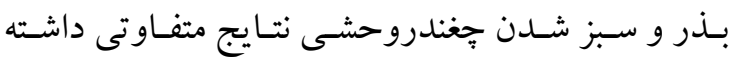

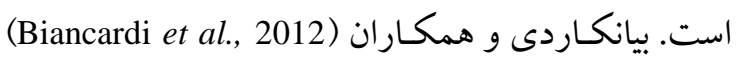
نشان دادند كه در شرايط مطلوب هفت تا لا روز بـراى

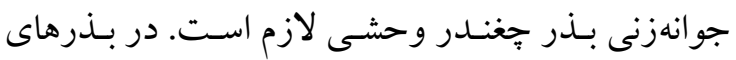
جمع آورى شده از منطقه بالاريس جوانهزنى بعـد از 11

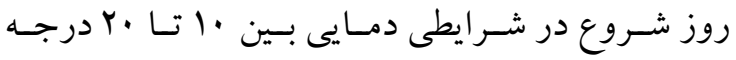

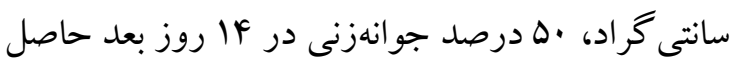

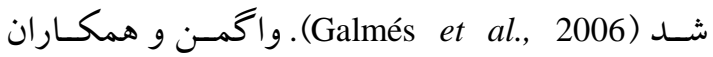
كزارش دادند كه •ه درصــ (Wagmann et al., 2010) بذرهاى جغندروحشى در جهار هفته بِس از كاشـت در

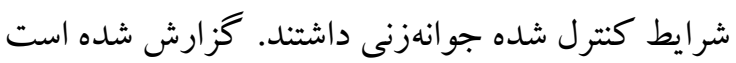

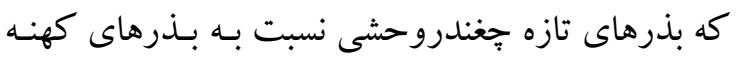

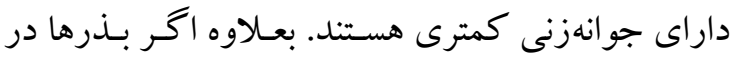

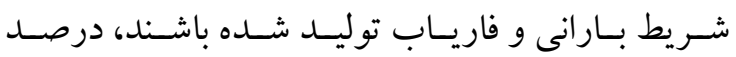

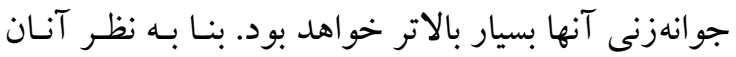

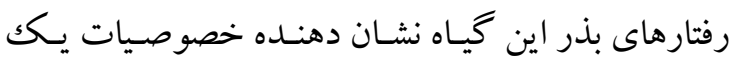

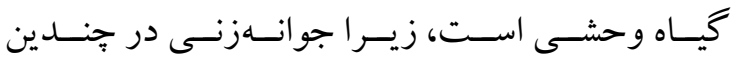

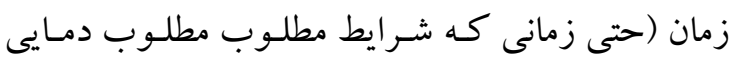

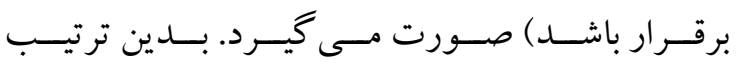

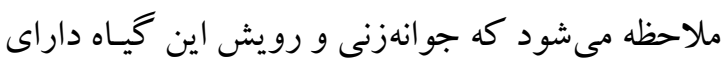

ترتيبه/

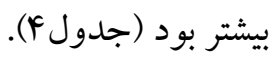

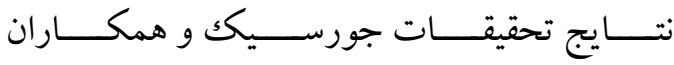
نشـان داد كه در دماهـاى بـايين (Jursík et al., 2003)

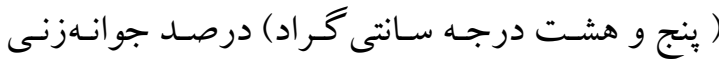

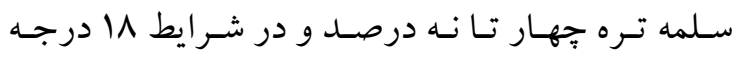
سانتى گر اد DQ درصد بذرهاى آن جوانسه زدنــد. تفـاوت

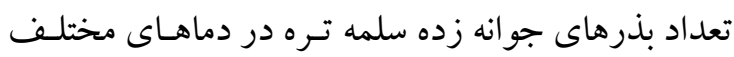

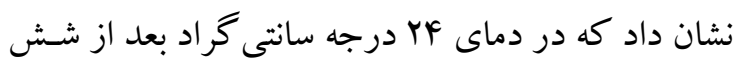

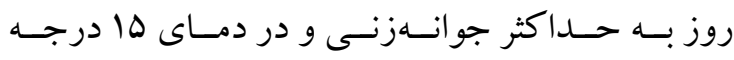

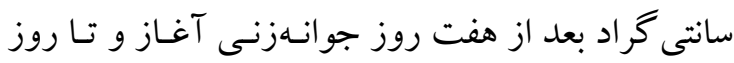

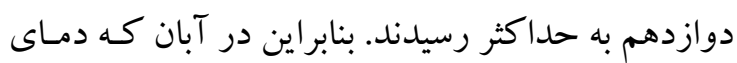

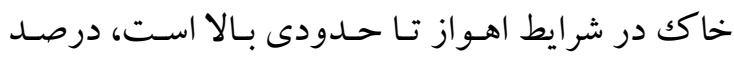

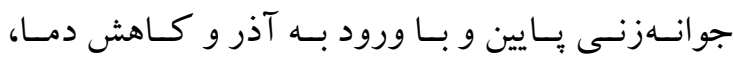

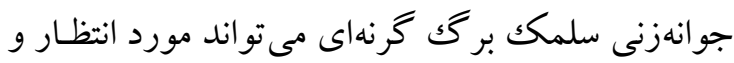

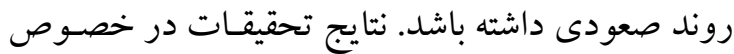

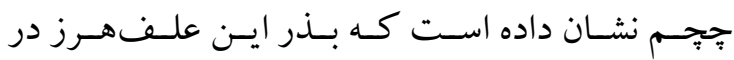

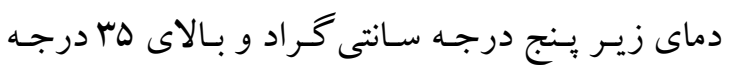

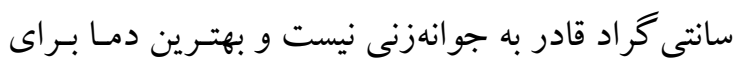

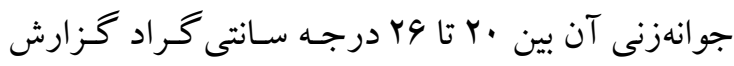
شد ( Steadman et al., 2003; Vila-Aiub et al., 2005 (ين) اسـتيدمن و همكـاران (Steadman et al., 2003)

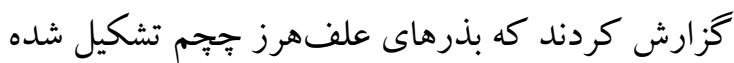

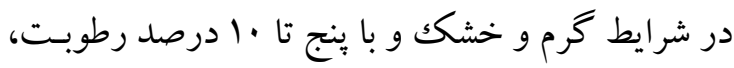

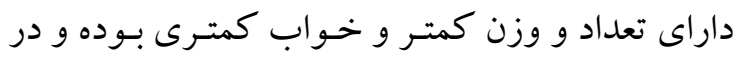

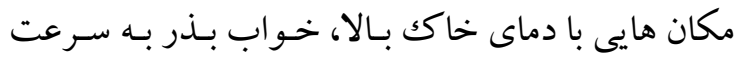

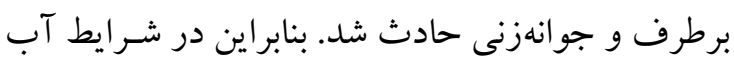
و هو ايى خوزستان با توجه به زمان كشت كلزا در اواخر

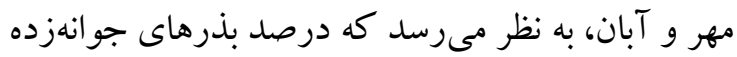

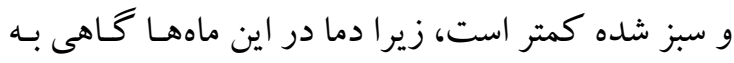

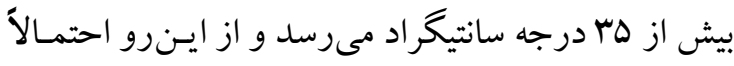

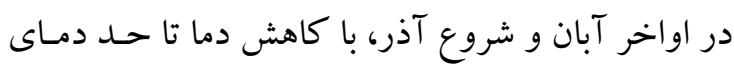

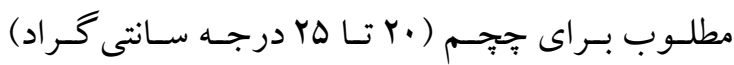

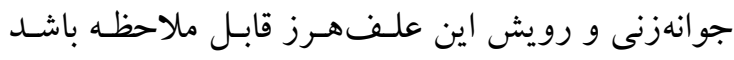




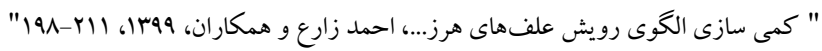

داد كه زمان لازم براى · ·، ·هو هو درصـد سـبز شـدن

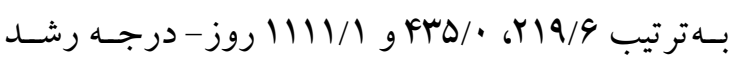

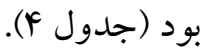

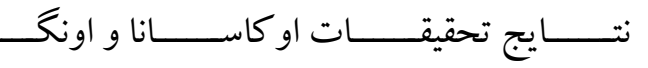
نشان داد كه درصـد (Okusanya and Ungar, 1983)

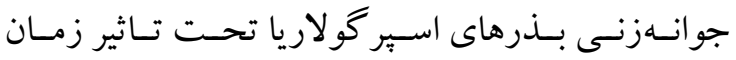

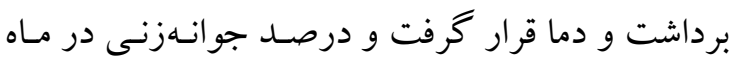

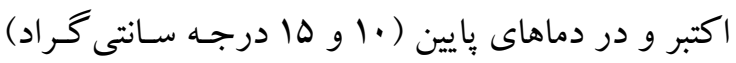

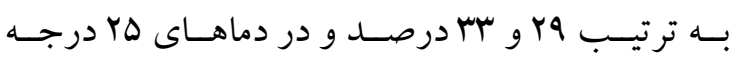

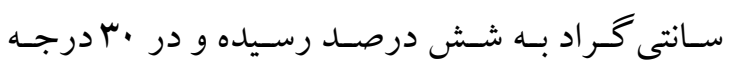

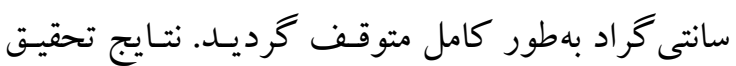

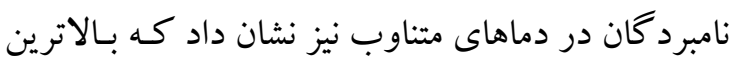

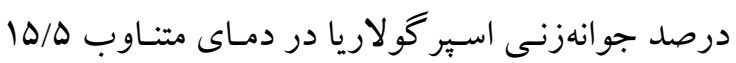

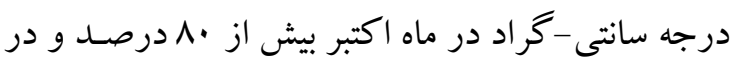

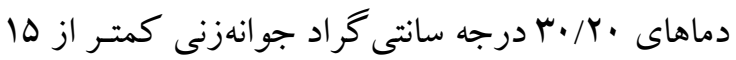
درصد بود.

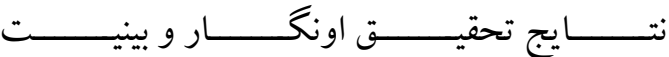

نشـان داد كـه اثـر اسـيد (Ungar and Binet, 1975) جيبرليك در دماهاى مختلـف برجوانسهنسى گونـهاى از

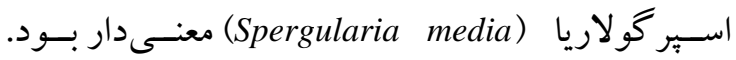
بيشترين درصد جوانهزنى (بيش از ه9 درصـد) درتيمـار

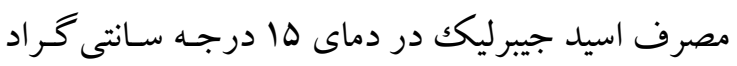
حاصل شد. با مصرف اسيد جيبرليكك در دماهـاى بـالا

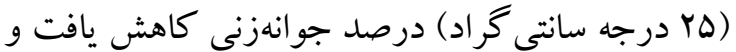
در طى ها روز به كمتر از •ودرصد رسيده و در تيمـار

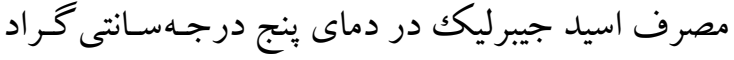
در طى ها روز، به بيش از •مدرصد رسـيد. در شـرايط

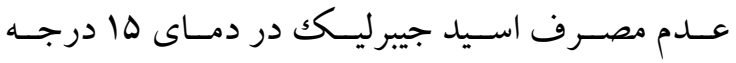
سانتى گراد در هفت روز اول، جوانهزنى ثابـت و كمتر

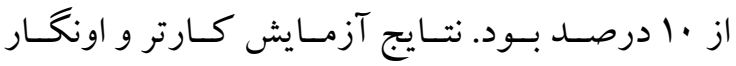
نشـان داد كـه جوانسزنسى (Carter and Ungar, 2004) اسبر گُ لاريا تحت تاثير دماهـاى متنـاوب قـرار گرفتـه و

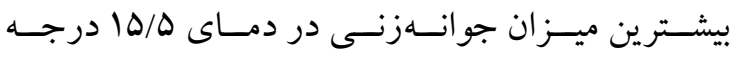

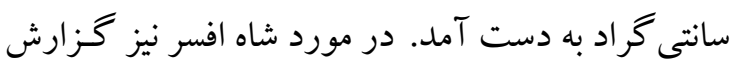

تو اترهـاى مختلـف بـوده و ممكـن اسـت جوانسهزنسى آن تا ماهها طول بكشد. بر اين اساس مى تـوان درجـات

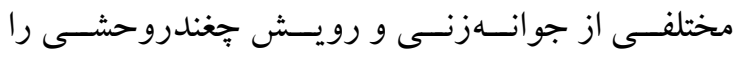

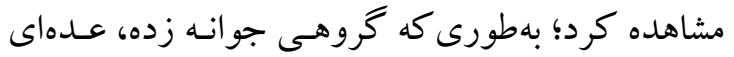

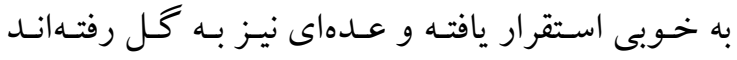
(Biancardi et al., 2012)

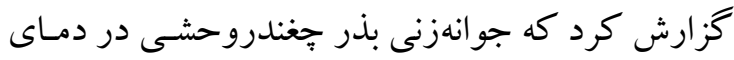

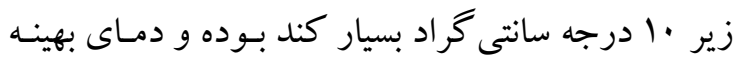

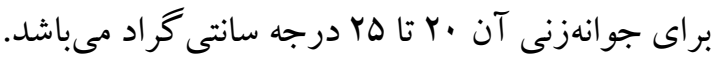

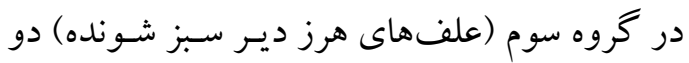

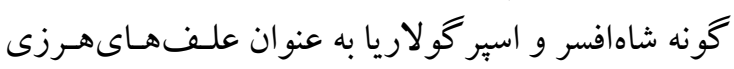
بودند كه نسبت به ساير علفهاى هرز ديرتر سبز شدند؛

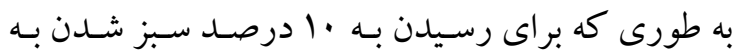

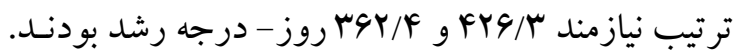

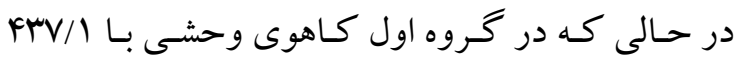
روز - درجه رشد به ·V درصد سبزشدن خود رسيده بود

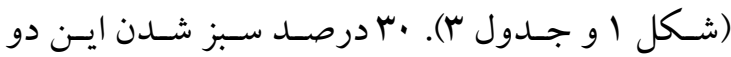

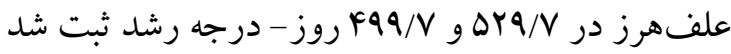

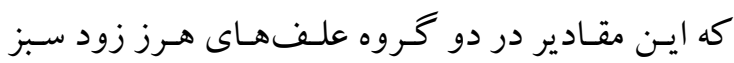
شونده و حد واسط بسيار بيشـتر بـود (جـدول ؟). نتـايج نشان داد كه زمان لازم براى رسيدن بـه •ه درصـد سـبز

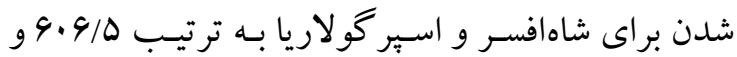

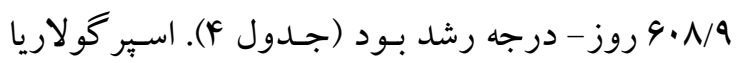
نسبت به شاه افسر زودتر سبز شد، اما سبز شـدن در طلى فصل رشد در شاه افسر نسبت به اسِر گولاريا كمتر بـود،

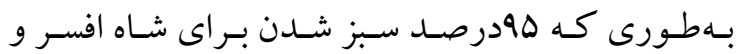

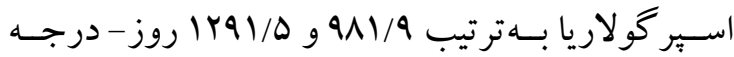
رشد به ثبت رسيد (جدول ؟). ايسن احتمـال وجـود دارد

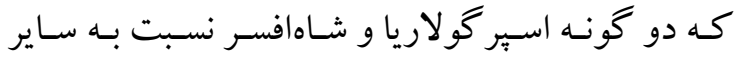

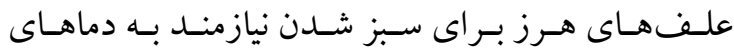

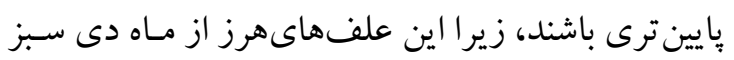

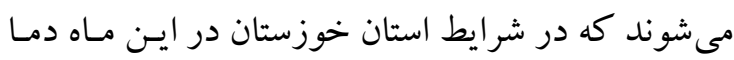

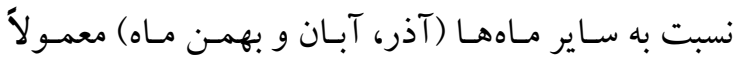
يايين تر است. نتايج سبزشدن كل علفهاىهرز نيز نشان 
(Corbin et al., 1994) جولى و جـان استون (Jolley and Johnstone, 1994)

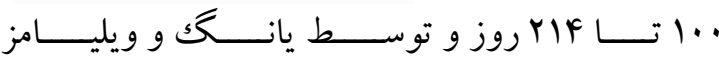
(Ying, and Williams, 2000) 199V به ترتيب T/9 و م/ ه هفته به دست آمـد. جـولى و

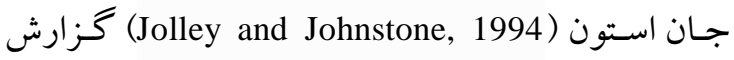
كردند كه با افزايش رطوبت ايش و افزايش دما ميزان تجزيـه

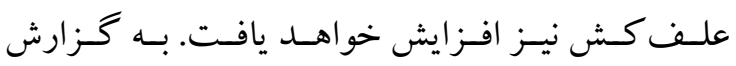

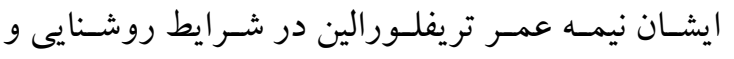

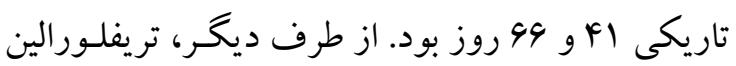

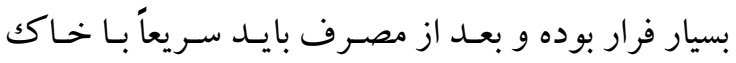

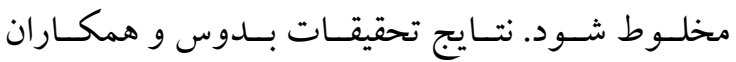
نشان داد كه فراريت تريفلور الين (Bedos, et al., 2006)

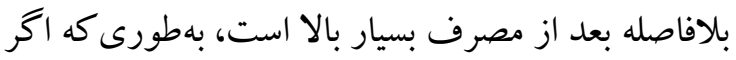

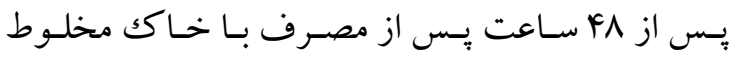

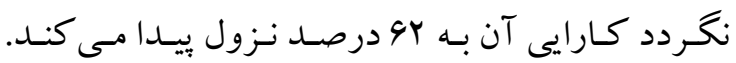

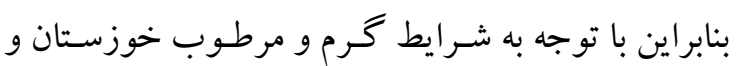

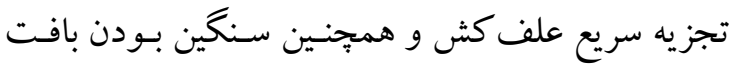

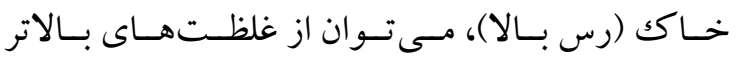
علف كث جهت كنترل بهتر علف هــاى هـرز استفاده كرد. مخلـوط كردن سـريع علـف كـش بـا خـاك نيسز مى تو اند باعث افزايش نيمه عمر علف كش شود.

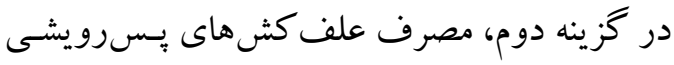

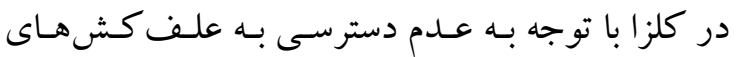

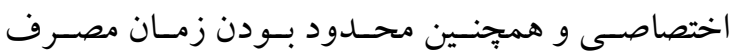

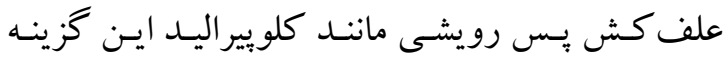

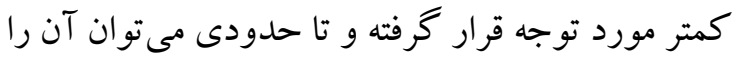

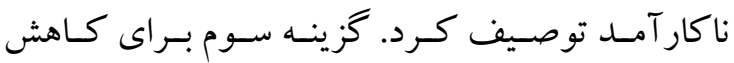

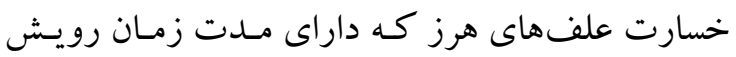

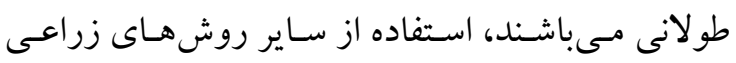

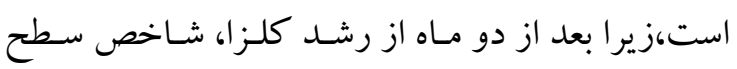

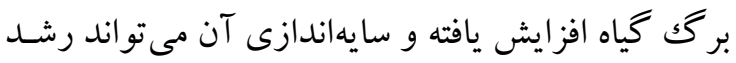

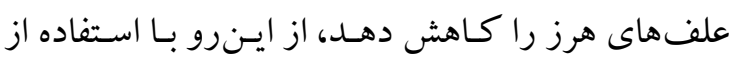

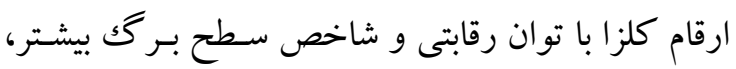

شـــه اسـتكه (Ghaderi-far, et al., 2010) كــه ايسن

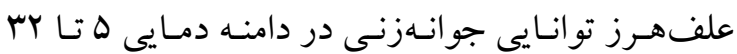

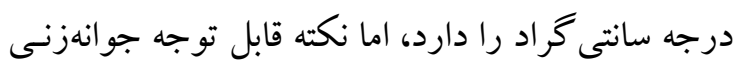

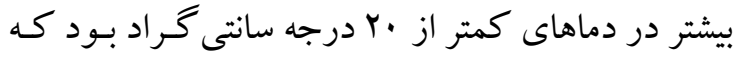

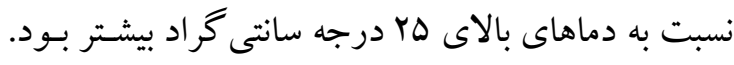

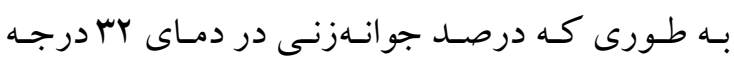

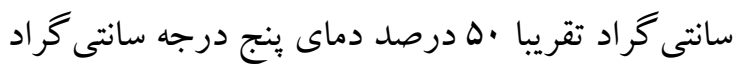

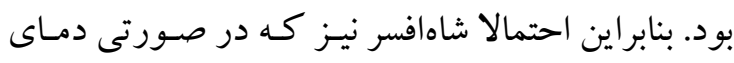

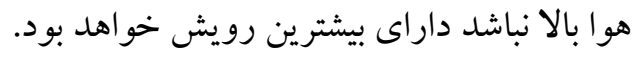

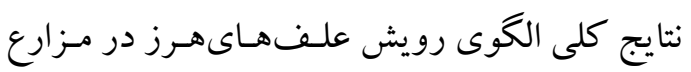

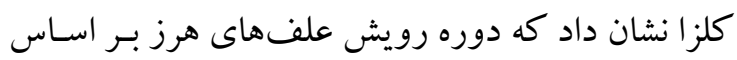

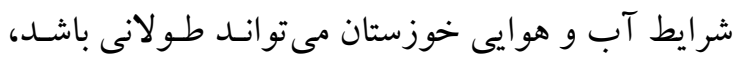

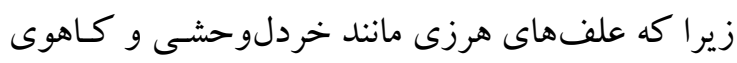

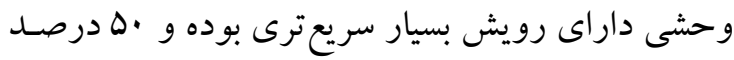

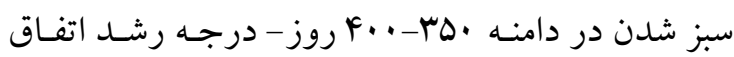

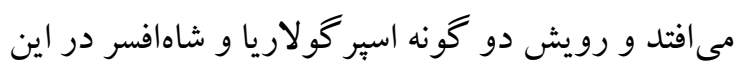

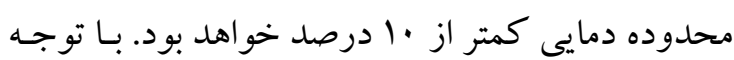

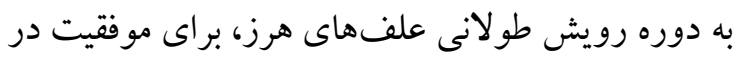

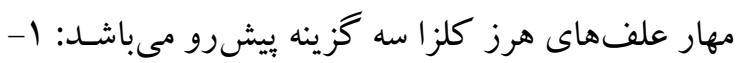
انتخاب علف كشهايى كه داراى نيمه عمر بيشترى بوده

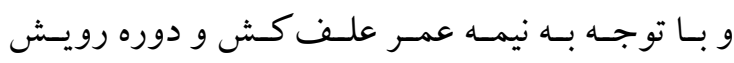

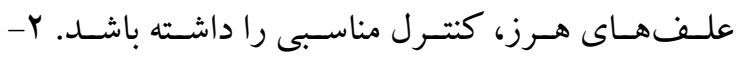

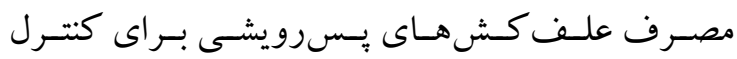

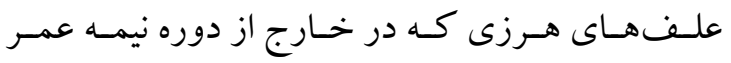
علف كـشهـاى خـاكك مصـرف رويـش دارنــ در نظـر

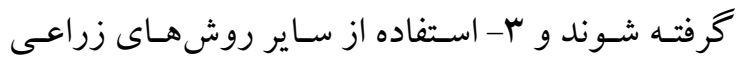

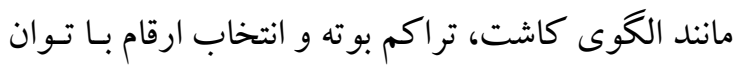

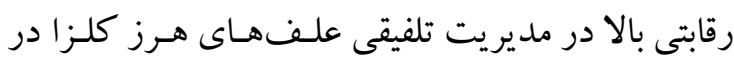
نظر كرفته شوند.

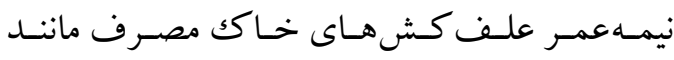

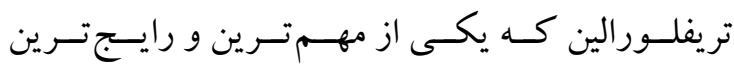
علف كشهاى بيش كاشت در كلز ا است، در تحقيقـات مختلف بسيار متفاوت كزارش شـده اسـت. بهطورى كـه

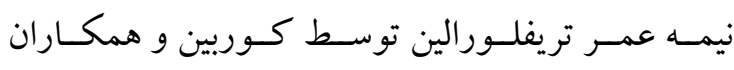




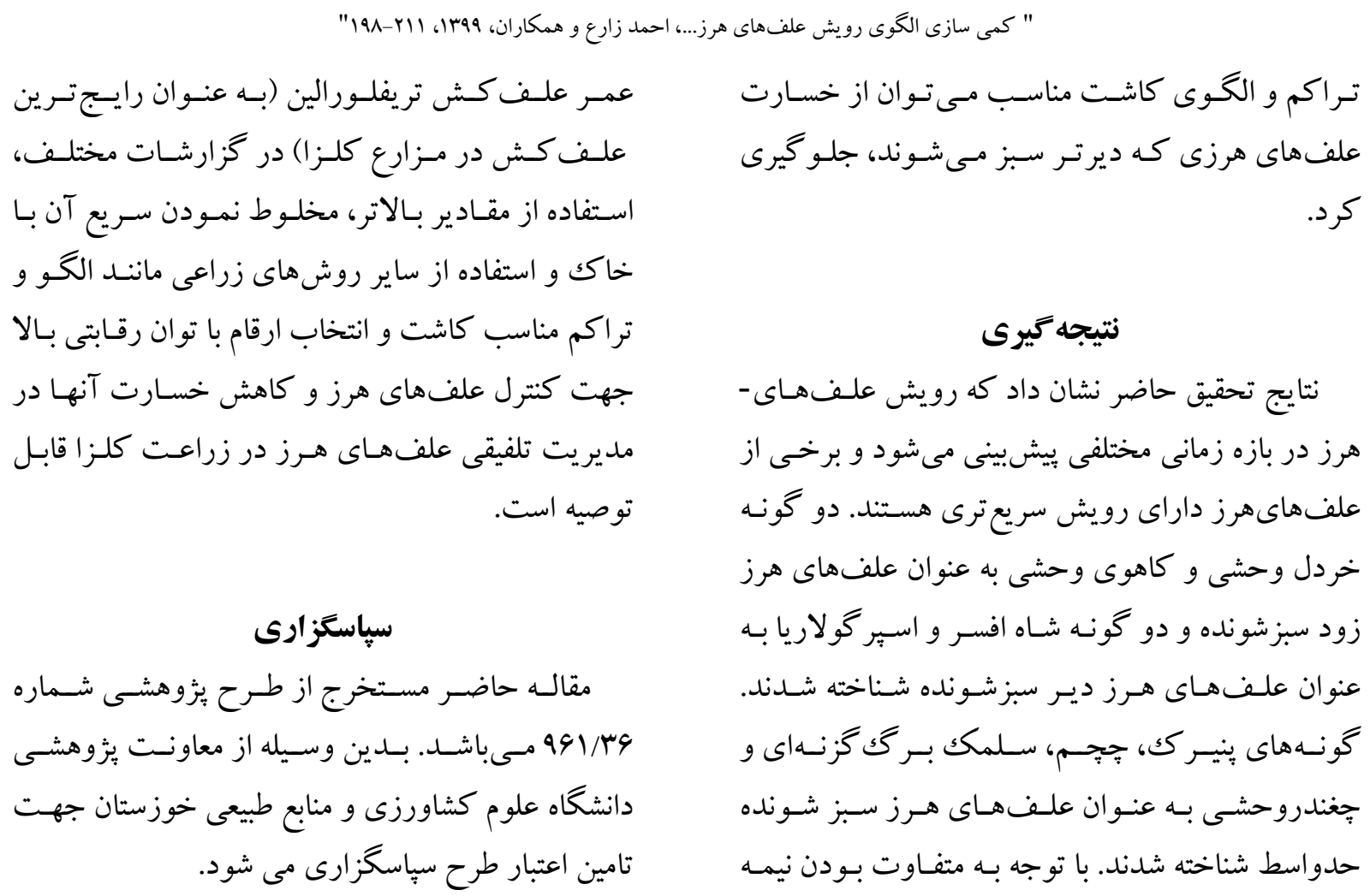

\section{References}

منابع مورد استفاده

Ansari, O., J. Gherekhloo, B. Kamkar and F. Ghaderi-Far. 2016. Breaking seed dormancy and determining cardinal temperatures for Malva sylvestris using nonlinear regression. Seed Sci. Technol. 44: 1-14.

Bedos, C, M. F. Rousseau-Djabri, B. Gabrielle., D. Flura, B. Durand, E. Barriuso and P. Cellier .2006. Measurement of trifluralin volatilization in the field: Relation to soil residue and effect of soil incorporation. Environ. Pollut. 144: 958-966.

Benech Arnold, R. L., C. M. Ghersa, R. A. Sanchez and P. Insausti. 1990. A mathematical model to predict Sorghum halepense (L.) Pers. Seedling emergence in relation to soil temperature. Weed Res. 30:91-99.

Biancardi, E., L. W. Panella and R. T. Lewellen. 2012. Beta Maritima: The Origin of Beets. New York, NY: Springer.

Cardina, J., C. P. Herms and D. A. Herms. 2011. Phenological indicators for emergence of large and smooth crabgrass (Digitaria sanguinalis and D. ischaemum). Weed Technol. 25: 141-150.

Carter, C. T. and I. A. Ungar. 2004. Relationships between seed germinability of Spergularia marina (Caryophyllaceae) and the formation of zonal communities in an inland salt marsh. Ann. Bot. 93: 119-125.

Corbin, B. R., Jr. M. McClelland., R. E. Frans., R. E. Talbert and D. Horton. 1994. Dissipation of fluometuron and trifluralin residues after long-term use. Weed Sci. 42:438-445.

Dorsainvil, F., C. Durr., E. Justes and A. Carrera. 2005. Characterisation and modelling of white mustard (Sinapis alba L.) emergence under several sowing conditions. Eur. J. Agron. 23:146-158.

Elahifard, E. and S. Kheyr Andish. 2016. Influence of burial depth on seedling emergence of wild mustard 


$$
\text { "نشريه علوم زراعى ايران"، جلد بيست و دوم، شماره r، تابستان }
$$

(Sinapis arvensis), junglerice (Echinochloa colona) and milk thistle (Silybum marianum). J. App. Res. Plant Ecophysiol. 3: 41-52. (In Persian with English abstract)

Elkarmi A., R. Abueideh and A. Zaiter. 2009. The growth of Chenopodium Murale irrigated with polluted and unpolluted water: a modeling approach. Aust. J. Basic Appl. Sci. 3: 1827-1837.

Forcella, F., R. L. Benech Arnold, R. Sanchez and C. M. Ghersa. 2000. Modeling seedling emergence. Field Crops Res. 67: 123-139.

Franke, A. C., N. S. Singh, A. S. Mcroberts, S. Nehra, R. Godara and J. Marshall 2007. Phalaris minor seed bank studies: longevity, seedling emergence and seed productions affected by tillage regime. Weed Res. 47: $73-83$.

Galmés, J., H. Medrano and J. Flexas. 2006. Germination capacity and temperature dependence in Mediterranean species of Balearic Islands. Investigacion Agraria Sistemas Recursos Forestales, 15:88-95.

Ghaderi-far, F., J. Gherekhloo and M. Alimagham, 2010. Influence of environmental factors on seed germination and seedling emergence of yellow sweet clover (Melilotus officinalis). Planta Daninha. 28: 463-469.

Goggin, D. E., S. B. Powles and K. J. Steadman. 2012. Understanding Lolium rigidum seeds: The key to managing a problem weed? Agron J. 2: 222-239.

Hartzler, R. G., D. D. Buhler and D. E. Stoltenberg. 1999. Emergence characteristics of four annual weed species. Weed Sci. 47:578-584.

Hermann, K., J. Meinhard, P. Dobrev, A. Linkies, B. Pesek, B. Hess, I. Machackova, U. Fischer and G. Leubner-Metzger. 2007. 1-Aminocyclopropane-1-carboxylic acid and abscisic acid duringthe germination of sugar beet (Beta vulgaris L.): a comparative study of fruits and seeds. J. Exp. Bot. 58: 3047-3060.

Jolley, A. V. and P. K. Johnstone. 1994. Degradation of trifluralin in 3 Victorian soils under field and laboratory conditions. Aust. J. Exp. Agric. 34: 57-65.

Jursík, M., J. Soukup, V. Venclová and J. Holec. 2003. Seed dormancy and germination of Shaggy soldier (Galinsoga ciliata Blake.) and Common lambsquarter (Chenopodium album L.) Plant, Soil Environ. 49: 511-518.

Kazerooni Monfared, E., P. Rezvani Moghaddam and M. Nassiri Mahallati. 2012. Modeling the effects of water stress and temperature on germination of Lactuca serriola L. seeds. Intl Res J Appl Basic Sci; 3: 1957-65.

Khalaj, H., I. Allahdadi, H. IranNejad., G., A. Akbari., M. MinBashi and M. A. Baghestani. 2012. Using nonlinear regression approach for prediction of cardinal temperature of canola and four common weeds. J. Agro Ecol. 1:21-33.

Letschert, J. P. W. 1993. Beta section Beta: bio geographical patterns of variation, and taxonomy. PhD Thesis, Wageningen Agricultural University, Netherland.

Morris, P. C., D. Grierson and W. J. Whttington. 1984. Endogenous inhibitors and germination of Beta vulgaris. J. Exp. Bot. 35:994-1002.

Myers, M. W., W. S. Curran, M. J. VanGessel, D. D. Calvin, D. A. Mortensen, B. A. Majek, H. D. Karsten 


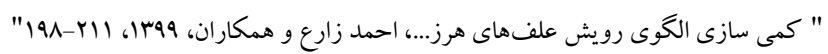

and G. W. Roth. 2004. Predicting weed emergence for eight annual species in the northeastern United States. Weed Sci. 52: 913-919.

Okusanya, O. T. and I. A. Ungar. 1983. The effects of time of seed production on the germination response of Spergularia marina. Physiol. Plant. 59: 335-342.

Owen, M. J., P. J. Michael., M. Renton., K. J Steadman and S. B. Powles. 2011. Towards large-scale prediction of Lolium rigidum emergence. I. Can climate be used to predict dormancy parameters? Weed Res. $51: 123-132$.

Pourreza, J. and A. Bahrani. 2012. Estimating cardinal temperatures of milk thistle (Silybum marianum) seed germination. American-Eurasian J. Agric. and Environ. Sci. 12: 1030-1034.

Scursoni, J. A., R. Benech-Arnold and H. Hirchoren 1999. Demography of wild oat in barley crops: effect of crop, sowing rate and herbicide treatment. Agron J. 91: 478-485.

Steadman, K. J., A. D. Crawford and R. S. Gallagher. 2003. Dormancy release in Lolium rigidum seeds is a function of thermal after-ripening time and seed water content. Funct. Plant Biol. 30:345-352.

Ungar, 1. A. and P. Binet. 1975. Factors influencing seed dormancy in Spergularia media (L.) C. Presl. Aquat. Bot. 1: 45-55.

Vila-Aiub, M., P. Neve., K. J. Steadman and S. B. Powles. 2005. Ecological fitness of a multiple herbicideresistant Lolium rigidum population: Dynamics of seed germination and seedling emergence of resistant and susceptible phenotypes. J. Appl. Ecol. 42: 288-298.

Wagmann, K., N. C. Hautekèete., Y. Piquot and H. Van Dijk. 2010. Potential for evolutionary change in the seasonal timing of germination in sea beet (Beta vulgaris subsp. maritima) mediated by seed dormancy. Genetica 138:763-773.

Ying, G. G. and B. Williams. 2000. Dissipation of herbicides in soil and grapes in a south Australian vineyard. Agric. Ecosyst. Environ. 78:283-289.

Yusefi, A., M. Rastgoo., M. Ghanbari Motlagh and M. Ebrahimi, 2013. Predicting seedling emergence of flixweed (Descurainia sophia (L.) Webb.) and hoary cress (Cardaria draba (L.) Desv.) in rapeseed (Brassica napus) field in Zanjan conditions. J. Plant Protect. 27: 48-54. (In Persian with English abstract)

Zare, A., H. Rahimian Mashhadi., M. Oveisi and R. Hamidi. 2014. Evaluation of wild oat seedling emergence after herbicide application in wheat. Iranian Weed Sci. 11: 37-49. (In Persian with English abstract) 
"نشريه علوم زراعى ايران"، جلد بيست و دوم، شماره r، تابستان ب99|

\title{
Quantifying field weeds emergence pattern of weeds in rapeseed (Brassica napus L.) under weather conditions of Khuzestan, Iran
}

\section{Zare, A. ${ }^{1}$, E. Elahifard ${ }^{2}$, Z. Taklifi Adnani ${ }^{3}$ and A. Roustaei ${ }^{4}$}

\begin{abstract}
Zare, A., E. Elahifard, Z. Taklifi Adnani and A. Roustaei. 2020. Quantifying field weeds emergence pattern of weeds in rapeseed under weather conditions of Khuzestan, Iran. Iranian Journal of Crop Sciences. 22(2): 198-211. (In Persian).
\end{abstract}

In order to quantifying emergence pattern of rapeseed weeds, this experiment was conducted in 40 plots (40 quadrates at Agricultural Sciences and Natural Resources University of Khuzestan, and 30 fields of Bavi (30 quadrates), Ahvaz, Iran, in 2016-2017 growing seasons was monitored, counted and recorded weekly. Three different emergence pattern of nine weed species were identified, Prickly lettuce (Lactuca serriola L.) and Wild mustard (Sinapis arvensis L) were identified as early-emerging species. Also salt sandspurry (Spergularia marina L.) and furrowed melilot (Melilotus sulcatus), were categorized as late- emerging species. However, five species including; mallow (Malva spp), rigid ryegrass (Lolium rigidum), sea beet (Beta vulgaris subsp. maritima), milk thistle (Silybum marianum L) and nettle-leaved goosefoot (Chenopodium murale L) were identified as medium-emerging species. Estimation of GDD $_{50}$ (time required to reach $50 \%$ emergence) showed that the minimum $\left.\left(323.62^{\circ} \mathrm{Cd}\right)\right)$ and maximum $\left(608.93{ }^{\circ} \mathrm{Cd}\right)$ growing degree day required by Lactuca serriola and Spergularia marina (L.), respectively. Whereas, $10 \%$ emergence of Spergularia marina and Melilotus sulcatus required $362.42{ }^{\circ} \mathrm{Cd}$ and $426.37{ }^{\circ} \mathrm{Cd}$, respectively. The results of weeds emergence pattern in rapeseed crop showed that the soil herbicides with longer half-life should be applied, and the application of post emergence herbicides and agronomic practices such as plant density and competitive ability of rapeseed cultivars are necessary components in integrated weed management.

Key words: Early-emerging weeds, Growing degree-days, Integrated weed management, Late-emerging weeds and Rapeseed.

\footnotetext{
Received: October, $2019 \quad$ Accepted: July, 2020

1. Assistant Prof., Agricultural Sciences and Natural Resources University of Khuzestan, Khuzestan, Iran (Corresponding author) (Email: ahmadzare@ asnrukh.ac.ir)

2. Assistant Prof., Agricultural Sciences and Natural Resources University of Khuzestan, Khuzestan, Iran

3. Former MSc Student, Agricultural Sciences and Natural Resources University of Khuzestan, Khuzestan, Iran

4. Former MSc Student, Agricultural Sciences and Natural Resources University of Khuzestan, Khuzestan, Iran
} 